\title{
Crenolanib Besylate
}

National Cancer Institute

\section{Source}

National Cancer Institute. Crenolanib Besylate. NCI Thesaurus. Code C106204.

The besylate salt form of crenolanib, an orally bioavailable benzimidazole targeting the platelet-derived growth factor receptor (PDGFR) subtypes alpha and beta and FMSrelated tyrosine kinase 3 (Flt3), with potential antineoplastic activity. Upon oral administration, crenolanib binds to and inhibits both wild-type and mutated forms of PDGFR and Flt3, which may result in the inhibition of PDGFR- and Flt3-related signal transduction pathways. This results in inhibition of tumor angiogenesis and tumor cell proliferation in PDGFR and/or Flt3 overexpressing tumor cells. PDGFR and Flt3, class III receptor tyrosine kinases, are upregulated or mutated in many tumor cell types. 